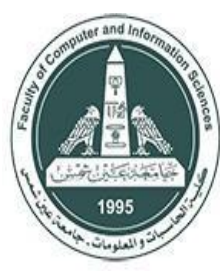

International Journal of Intelligent Computing and Information Sciences

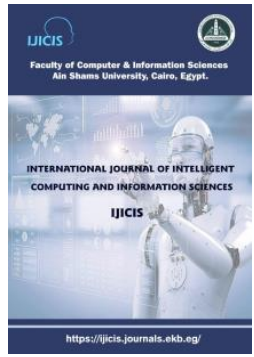

\title{
Comparison of Satellite Images Classification Techniques Using Landsat-8 Data for Land Cover Extraction in Alexandria, Egypt
}

Soha A. Mohamed*

Egyptian Ministry of Higher Education, Egypt

igsr.soha.ahmed@alexu.edu.eg

Received 2021-6-2; Revised 2021-8-18; Accepted 2021-8-18

Abstract: Accurate extraction of land cover types from thematic maps using satellite images still constitutes a critical challenge. The selection of the optimal satellite image classification algorithm is considered a crucial prerequisite for successful classification results that are required for various applications. The perfect classification algorithm is considered a significant key for improving classification accuracy. The principal foci of this study were to compare, analyze the performance, and assess the effectiveness of four classification algorithms including ISODATA, K-means, pixel-based and segment-based classification techniques to attain accurate land cover extraction from remote sensing data. The classified images were validated with ground control points obtained from field visits in addition to the DigitalGlobe and Google Earth Pro. The overall accuracy of the ISODATA, K-means, pixel and segment-based classifications were $81.82 \%, 77.27 \%, 92.42 \%$, and $87.88 \%$, respectively. The results revealed that the pixel-based classification presented a superior in terms of the overall accuracy and kappa coefficient.

Keywords: Image classification, maximum likelihood classifier (MLC), clustering, $k$-mean, ISODATA.

\section{Introduction}

Remote sensing images ensure a sustainable, effective, and up-to-date source of data to get land use and land cover (LULC) information. The extraction of an accurate and recent LULC information is a prerequisite for distinct applications such as environmental monitoring, spatial planning, and many other applications. Image classification can be defined as the process of getting information from satellite imageries (Rokach and Maimon, 2005; Choodarathnakara et al., 2012; Goswami et al., 2014; Jog and Dixit, 2016; Sathya and Deepa, 2017; Altaei and Ahmed, 2018). Campbell (2002) defined the satellite image classifier as a computer program that divides the image into various distinct land classes using mathematical algorithms. Lu and Weng (2007) presented many steps that should be performed

* Corresponding author: Soha A. Mohamed

Egyptian Ministry of Higher Education, Egypt

E-mail address: igsr.soha.ahmed@alexu.edu.eg 
preceding the image classification including image preprocessing (such as image enhancement and radiometric correction), choice of training samples and the selection of the optimal classification algorithm in addition to the classification accuracy assessment.

Image classification can be broadly assorted into hard and soft or unsupervised and supervised, or non-parametric and parametric (Al-Ahmadi and Hames, 2009; Choodarathnakara et al., 2012; Patil et al., 2012; Thakur et al., 2017; Yousefia et al., 2015; Madhura and Venkatachalam, 2015; Tonyaloğlu et al., 2021). Hard classifiers assumed that the pixels are pure, and the mixed pixels to be dispensed to only one class (Richards, 1993; Jensen, 1996). Mixed pixels are those pixels that do not belong to only one land cover class, but it distributed in many other land cover classes (Hu et al., 2014). In the real world, pixels may have more than one class due to the heterogeneity of the land cover constituting that pixel such as in urban areas. Accordingly, soft or sub-pixel or fuzzy classifiers allow a pixel to be allocated to several land cover classes rather than to only one class (Foody 1996; Foody 1997; Eastman and Laney 2002; Choodarathnakara et al., 2012).

Supervised classifiers are requiring prior knowledge of the existed land cover types (Thakur and Maheshwari, 2017). The supervised classifiers categorize images into homogeneous classes depending on the training (sample) data (Goswami et al., 2014). Parallelepiped, maximum likelihood, minimum distance, and Mahalanobis distance are the common supervised classifiers. Patil et al. (2012) compared the maximum likelihood classifier (MLC) and minimum distance classifiers to detect the LULC using the Landsat-TM image acquired in 1999. Madhura and Venkatachalam (2015) applied minimum distance, maximum likelihood classifier, and Mahalanobis classifier to investigate land cover in the South of India. Their results revealed that the maximum likelihood algorithm revealed the best results. Yousefia et al. (2015) discussed six supervised classification algorithms including the minimum distance, Mahalanobis distance, maximum likelihood, artificial neural network, spectral angle mapper, and support vector machine (SVM) to detect the land use in Iran. The maximum likelihood and support vector machine algorithms exhibited the best accuracy in land use mapping. Sathya and Deepa (2017) compared between parallelepiped, minimum distance, maximum likelihood, and k-nearest neighbor supervised techniques. Unsupervised classification, which is also known as clustering, is used to partition the satellite image into homogeneous clusters (classes). Each cluster is corresponding to a specific land cover type (Usman, 2013; Goswami et al., 2014; Phyo et al., 2015; Mahi et al., 2016). Clustering algorithms are divided into pixel-based and object-based methods (Phyo et al., 2015). Mahi et al., (2016) applied K-harmonic means (KHM), cluster validity indices (CVI) and an angle-based method to classify multispectral remotely sensed images. The parametric and non-parametric classifiers are categorized beneath the supervised classification techniques. Bayesian, Naïve Bayes, and decision trees are examples of the parametric classifiers (Sonawane and Dhawale, 2016; Thakur and Maheshwari, 2017). Logical regression and multilayer perceptron are non-parametric classifiers (Sonawane and Dhawale, 2016; Thakur and Maheshwari, 2017).

Image classification can be as well divided into pixel-based and segment-based classification techniques. Several authors applied object-based classification to extract accurate land cover information including Frauman and Wolff, (2005); Matinfar et al., (2007); Radoux and Defourny, (2007); Trias-Sanz et al., (2008); Blaschke, (2010); Robertson and King, (2011); Verma et al., (2014); Özkan and Yeşil, (2016); Mohamed and El-Raey, (2018); Mohamed and El-Raey, (2019a, 2019b); Mohamed, (2019); Tonyaloğlu et al., (2021); Deur et al., (2021). The processing units in the pixel-based and segment-based are the single pixels and segments (objects) respectively (Antunes et al., 2003; Drăguţ et al., 2010; Verma et al., 2014).

Satellite image classification has great significance to obtain information relating to the Earth's resources for different environmental applications. The selection of the optimal classification techniques is still a challenge. The aim of this study was to compare between four classification techniques 
including unsupervised (ISODATA, K-means) and supervised (pixel-based and segment-based) classification techniques to attain accurate land cover maps from remote sensing data. The classification results were compared with one another. This study is performed for the first time in Alexandria City which considered the second capital of Egypt. No, similar previous studies are available for the study area.

\section{Study Area}

Alexandria is an Egyptian governorate and considered the second capital of Egypt. Alexandria is in the north-central part of Egypt between $30^{\circ} 50^{\prime}$ to $31^{\circ} 40^{\prime}$ north and $29^{\circ} 40^{\prime}$ to $32^{\circ} 35^{\prime}$ east and extending for about $32 \mathrm{~km}$ along the coast of the Mediterranean Sea. The total area is approximately $2,679 \mathrm{~km}^{2}$ with a total population of $5,200,000$ and a population density of $1,900 / \mathrm{km}^{2}$ (CAPMAS, 2019). The study area is shown in Figure 1.

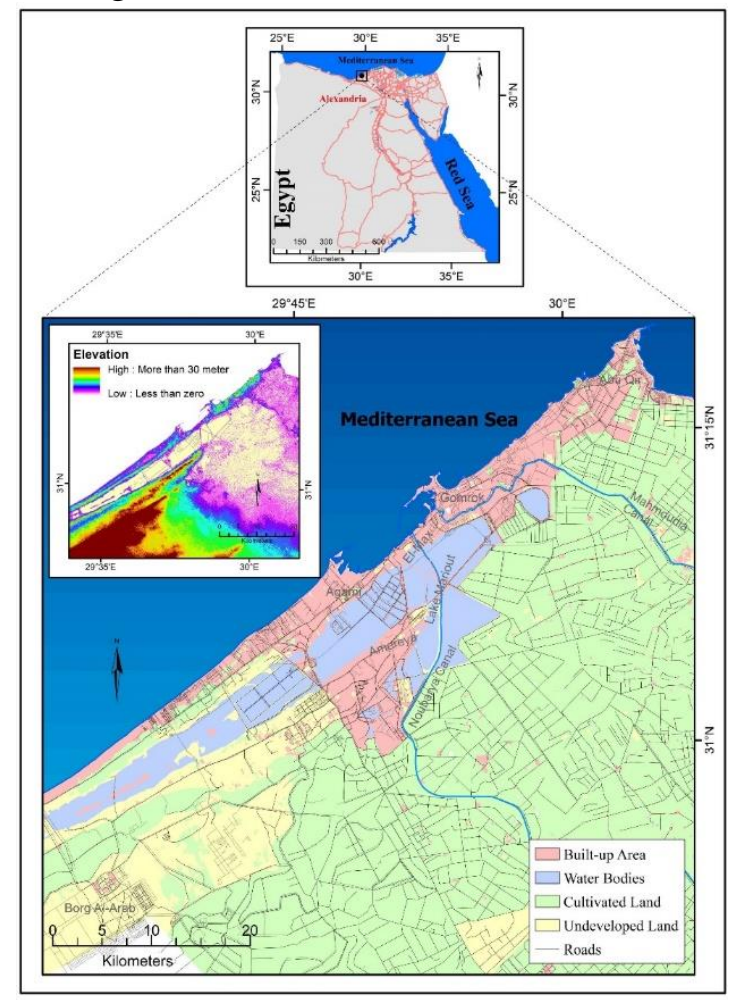

Figure 1: Location of the study area

\section{Data Acquisition}

Landsat-8 (OLI/TIRS) satellite image is acquired freely from the U.S. Geological Survey's website (http://earthexplorer.usgs.gov/). All details about the satellite image are described in Table 1. 
Table 1: Description of Landsat (OLI/TIRS) satellite image

\begin{tabular}{l}
\multicolumn{1}{c}{ Image description } \\
\hline Acquisition Date: 2018-11-03 \\
OLI/TIRS-Sensor: Landsat 8 \\
Path/Row: 178-38 \\
Spatial Resolution: $30 *$ \\
Number of Bands: 11 \\
Format: Geotiff \\
Projection system: UTM \\
Datum: WGS84
\end{tabular}

\footnotetext{
*The resolution of the panchromatic band (band 8) is 15 meters and the resolution of Landsat-8 bands 10, 11 is 100
} meters.

\section{Methodology}

The methodology of the present study is divided into four main stages: (1) the first stage is the image preprocessing which encompassed the conversion to TOA (top-of-atmosphere reflectance); (2) layer stacking (combine bands from 1 to 7 together into a single image); (3) resolution merge (merge stacked dataset with band-8 (panchromatic band) to get high-spatial resolution), and (4) the image mask (sub-set image to match the study area). The second stage included the collection of training areas, the final stage was the image classification techniques. Figure 2 presented the flow chart diagram of the applied methodology. 


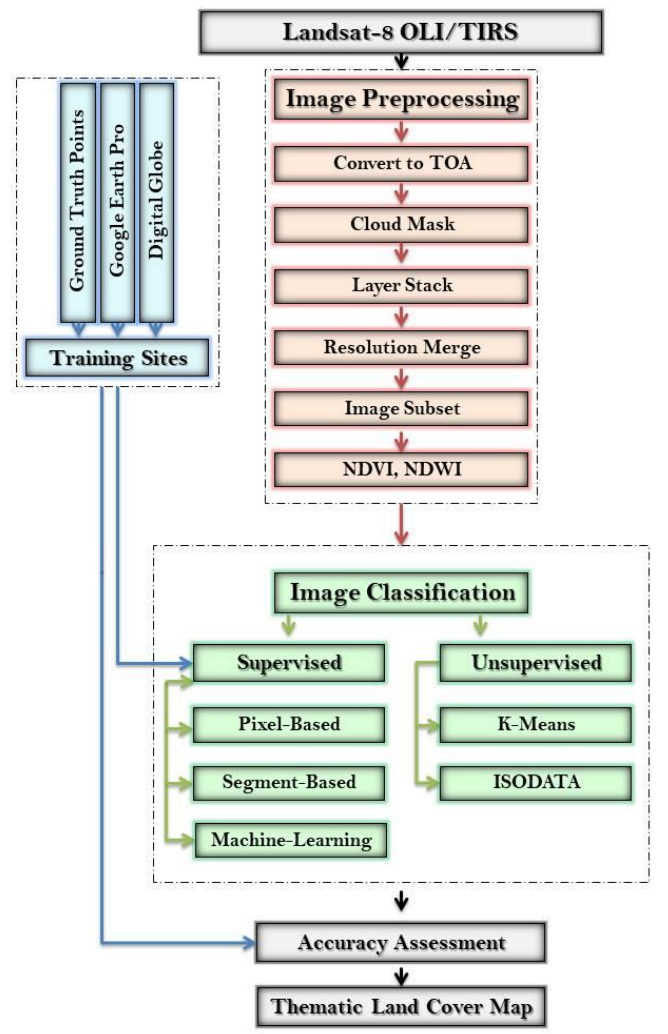

Figure 2: Flow diagram for the study methodology

\subsection{Image Preprocessing}

Image preprocessing involved the radiometric correction to reduce, eliminate and correct errors in the digital numbers of the image. Consequently, the radiometric correction enhances the quality and interpretability of the satellite image. The at-sensor reflectance (also known as top-of-atmosphere (TOA) reflectance) is calculated using Eqs. (1) and (2).

$$
\begin{gathered}
\rho_{\lambda^{\prime}}=\mathrm{M}_{\rho} \mathrm{Q}_{\text {cal }}+\mathrm{A}_{\rho} \\
\text { https://landsat.usgs.gov/using-usgs-landsat-8-product }
\end{gathered}
$$

Where $\rho_{\lambda^{\prime}}$ is the TOA reflectance, $M_{\rho}$ is the band multiplicative value, $A_{\rho}$ is the band additive value, $Q_{\text {cal }}$ is the digital numbers (DN) of the Landsat satellite bands.

$$
\rho_{\lambda}=\frac{\rho \lambda}{\operatorname{Sin}(\Theta S E)}
$$

https://landsat.usgs.gov/using-usgs-landsat-8-product

Where, $\rho \lambda$ is the TOA planetary reflectance and $\theta$ SE is the sun elevation angle.

The next image preprocessing was the layer stacking which combines the multiple-image bands together. As a subsequent preprocessing step, bands (1, 2, 3, 4, 5, 6, and 7) are incorporated into a multi-layer raster stack. Then, the spatial resolution merge is applied to integrate the different spatial resolutions of Landsat multispectral bands (30 meters) with the panchromatic band (15 meters) to improve the spatial resolution of the Landsat image. Finally, the entire scene of the Landsat- 8 image which covers $185 \times 185 \mathrm{~km}^{2}$ is clipped to match the study area of interest. 


\subsection{Satellite Image Classification}

Image classification in this research is divided into unsupervised (K-means and ISODATA) and supervised techniques (pixel-based and segment-based maximum likelihood classifiers). K-means algorithm is an unsupervised classifier that partition image pixels into K-clusters (classes) iteratively, where pixels are assigned to the cluster with the nearest mean in the feature space (Vimala et al., 2020; Abdu et al., 2014). The feature space is a two-dimensional space to measure the similarity in the clustering algorithm. The K-means classifier requires in advance the identification of the maximum number of iterations and the convergence threshold. The first iteration in the K-means is to suppose random cluster centers (centroids) then the pixels are assigned based on the shortest distance to the center. The standard deviation for each cluster and the distance between cluster centers are calculated. The clusters are merged only if the distance between them is less than the user-defined threshold. Whereas, if the distance between clusters was greater than the user-defined threshold, a next iteration will be performed with the new cluster centers obtained from the previous iteration. Then, the distance between the pixels and the new centroid is recalculated using the Euclidian distance (ED), and the pixel is allocated to the class depending on the Euclidian distance. Alamri et al. (2016) expressed the Euclidean distance by:

$$
\mathrm{d}_{\mathrm{E}}(\mathrm{x}, \mathrm{y})=\sum_{\mathrm{i}=1}^{\mathrm{d}}\left(\mathrm{x}_{\mathrm{i}}-\mathrm{y}_{\mathrm{i}}\right)^{2}
$$

A loop of iterations is continued until the maximum number of iterations is reached and no more " $\mathrm{k}$ " centroids location changes are made (new centroids and old centroids were the same, and the distance was zero). Phyo et al., (2015) represented the K-means algorithm mathematically by Eq. (4):

$$
\mathrm{J}_{\mathrm{k}-\mathrm{mean}}=\quad \sum_{k=1}^{K} \sum_{j \in S_{k}} d^{2}\left(x_{j}, c_{k}\right)
$$

Where, $\mathrm{k}$ is the number of clusters; $\mathrm{xj}$ is the pattern $\mathrm{j}$ evaluated in a relation to the centroid and $\mathrm{d}^{2}\left(\mathrm{x}_{\mathrm{j}}, \mathrm{c}_{\mathrm{k}}\right)$ is the distance between pattern $\mathrm{xj}$ and centroid ck.

Iterative Self-Organizing Data Analysis Technique Algorithm (ISODATA) classifier iteratively assigned the pixels to the clusters using the minimum spectral distance between pixels and an arbitrary mean cluster. The spectral distance between each pixel and each cluster mean is calculated and the pixel is assigned to the cluster with the nearest mean. In the next new iteration, the calculated clusters' means are recalculated, and the pixels are shifted and allocated to new clusters with the closest mean. According to Swain (1973), the ISODATA classifier is terminated if there is no change between the successive iterations.

Supervised classification in this study is divided into the pixel-based and the segment-based classification. The pixel-based classification assigned the unknown pixel by comparing its spectral signature properties with the collected training samples with the available land cover types in the scene (Lu and Weng, 2007). The segment-based classification partitions the raster image into segments depending on the spectral similarity of pixels. The homogeneous pixels are assigned to these spectrally similar image segments. Different similarity tolerance is applied to get different segmentation results. The smaller similarity tolerance value generates more detailed segmentation results, and the large similarity tolerance may absorb the small land cover classes into larger objects which may affect the land cover type's discrimination. In supervised classification, the satellite images are analyzed using representative training sample sites for the various land cover types present in the image. The training areas are representative samples of the present cover type in the satellite image. The training areas are 
collected from field visits and they describe the spectral characteristics for each land cover type. The supervised classifiers compare each pixel in the image with the collected training areas. Alamri et al. (2016); Sathya and Deepa (2017) classified training samples into two types, the first type is used in image classification and the second type is used in classification accuracy assessment. According to Prasad et al. (2015), the spectral signatures are created from selecting training sites based on the identification of similar areas in different covers and land uses, combining the knowledge of the area for a proper selection of the regions of interest (ROI).

\subsection{Classification Accuracy Assessment}

Perumal and Bhaskaran (2010); Laborte et al. (2010); Alamri et al. (2016) investigated the accuracy of the satellite image classification. Prasad et al. (2015) presented four techniques to improve classification accuracy form ancillary data in addition to six approaches for improving classification accuracy using remote sensing data. Classification of remotely sensed data depends on several factors such as landscape complexity, image preprocessing, image processing and classification algorithm (Prasad et al., 2015). Kappa coefficient has been introduced the as a statistical index for accuracy assessment in enormous remote sensing researches (Foody, 2020). Parraga-Alavaa et al. (2021) presented kappa coefficient mathematically as seen in Eq. (5).

$$
\text { Kappa coefficient }=\quad \frac{\mathrm{N} \sum_{\mathrm{i}=1}^{\mathrm{r}} \mathrm{x}_{\mathrm{ii}}-\sum_{\mathrm{i}=1}^{\mathrm{r}}\left(\mathrm{x}_{\mathrm{i}+} \cdot \mathrm{x}_{+\mathrm{i}}\right)}{\mathrm{N}^{2}-\sum_{\mathrm{i}=1}^{\mathrm{r}}\left(\mathrm{x}_{\mathrm{i}+} \cdot \mathrm{x}_{+\mathrm{i}}\right)}
$$

Where, $\mathrm{r}$ is the number of rows and columns in the confusion matrix; $\mathrm{N}$ is the total number of pixels in the confusion matrix; $x_{i i}$ is major diagonal element for class $i$; $x_{i+}$ is the total number of pixels in row $i$; $\mathrm{x}_{+\mathrm{i}}$ is the total number of pixels in column $\mathrm{i}$. In this study, the field visits are performed for the collection of training areas required for supervised classification and for the verification of classification accuracy assessment. During the field survey, the coordinate of different land cover samples is calculated using GPS. DigitalGlobe and Google earth pro are used for the inaccessible areas in the study area.

\section{Results and Discussion}

The top-of-atmosphere (TOA) reflectance obtained using Eqs. (1) and (2) are presented in Figure 3 .

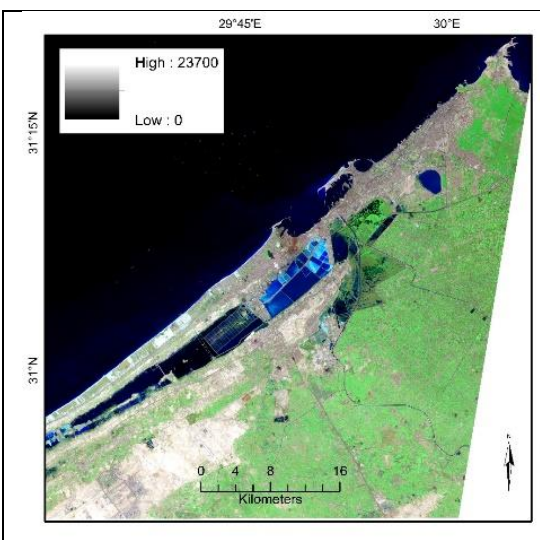

a. DN values

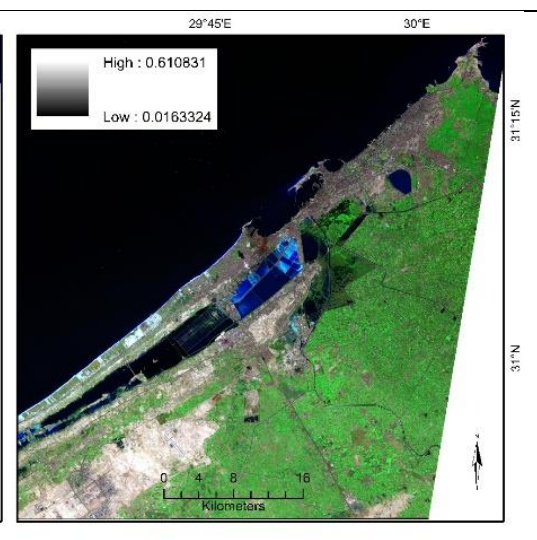

b. TOA reflectance

Figure 3: TOA conversion

The unsupervised classification results including the ISODATA and K-mean approaches can be seen in Figure 4. The results revealed that the ISODATA classifier showed better results than the K- 
means. The class of the barren land with vegetation cover in the K-means is misclassified and considered under-estimated and overlapped with both of the bare soill and the vegetated areas. Both of the classifiers succeded in the discrimination between urban areas and other land cover types. The two classifiers failed somewhat in the discrimination between various vegetation types in addition to the different bare soil types. The training areas required for the pixel-based classification are identified using draw polygon and seed pixels tools in Erdas Imagine software version 2014, while the segmentbaed trainin areas are identified in the Terrset software using the segtrain module. The training areas are presented in Figure 5. The pixel-based and segment-based classification results are illustrated in Figure 6. From the figure, it can be seen that the pixel-based classification showed better results than the segment-based approach. The segment-based classification generated large homogenous areas for each land cover types which seems to be inappropriate for the study area.

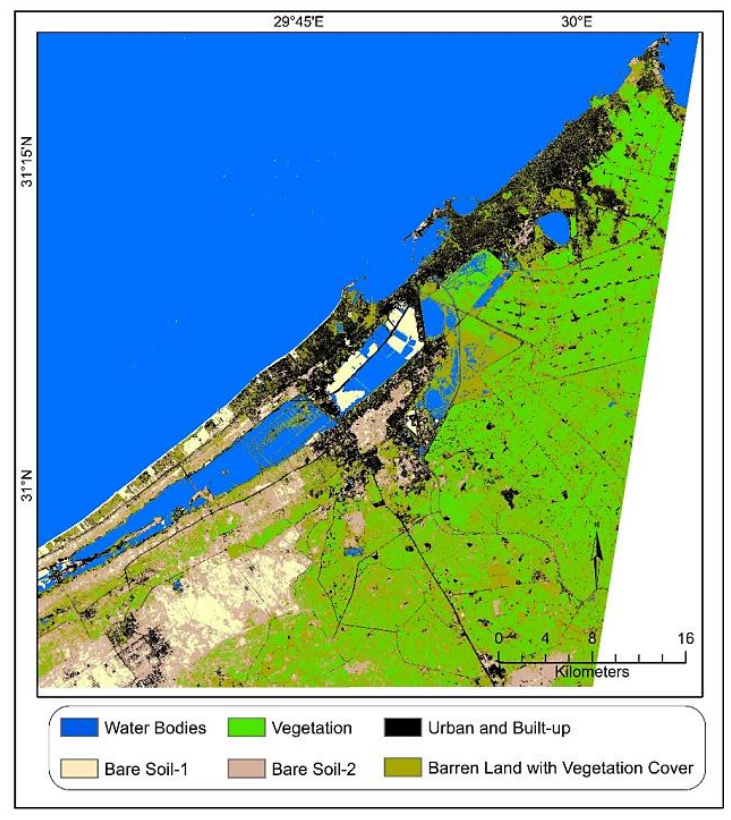

a. ISODATA classification

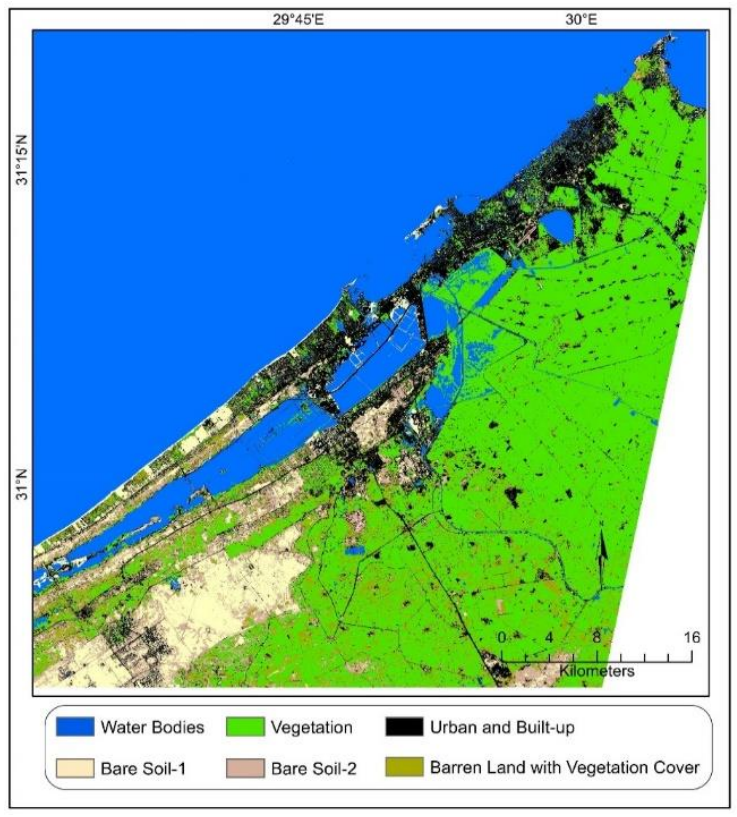

b. K-means classification

Figure 4: Unsupervised classification 


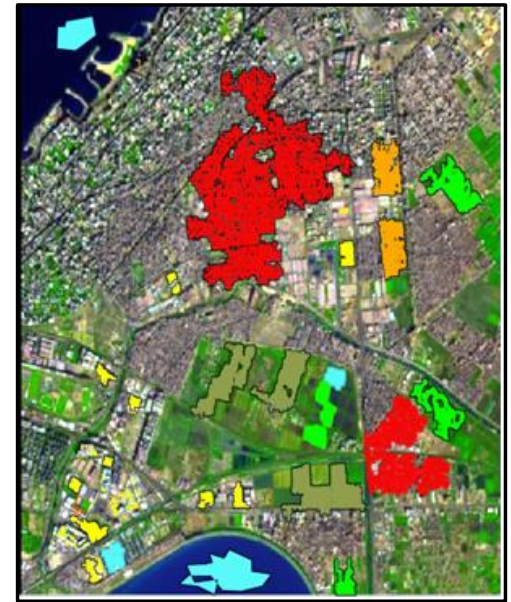

Water Bodies

Bare Soil1

Barren with Vegetation Cover

a. Pixel-based classification

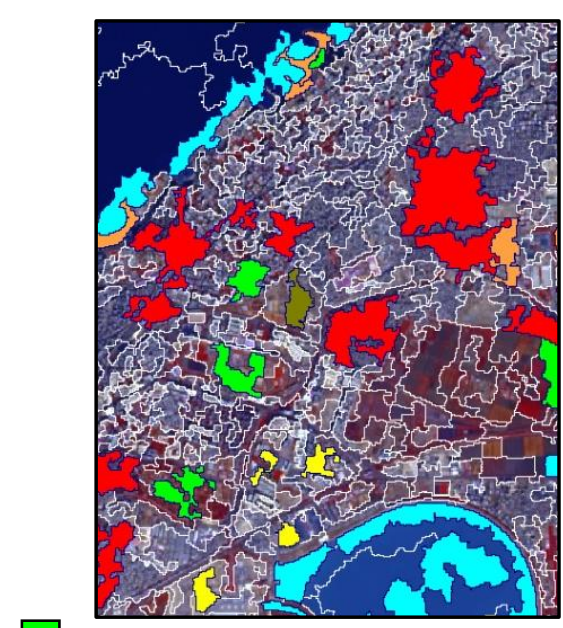

Vegetation

Bare Soil2

Urban and Built-up

b. Segment-based classification

Figure 5: The selected training samples

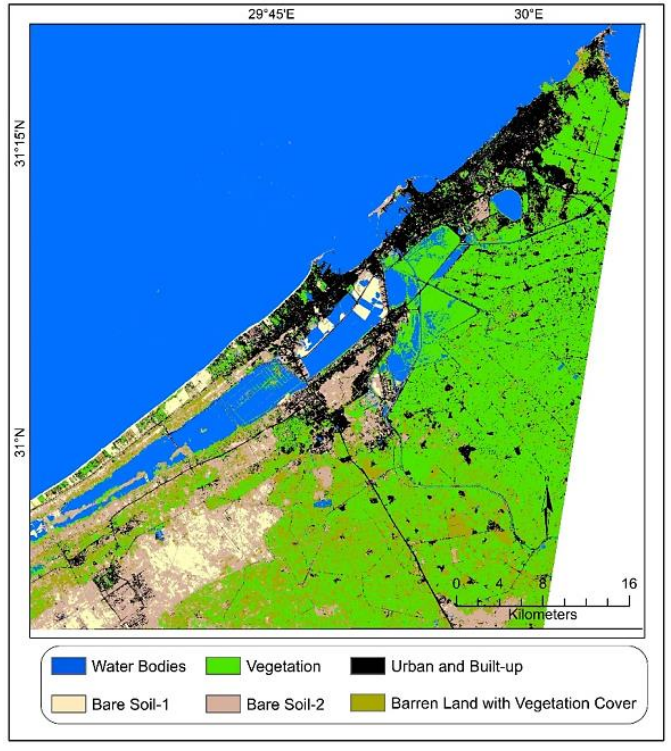

a. Pixel-based classification

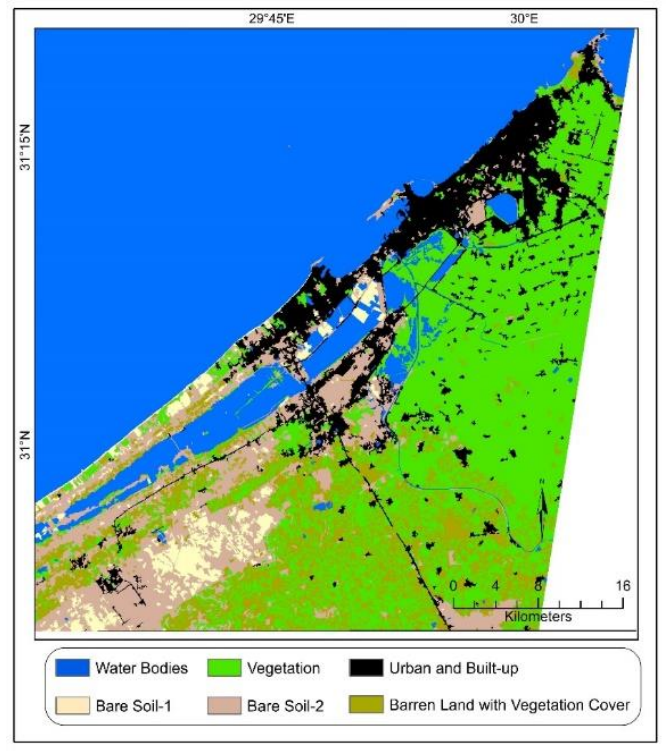

b. Segment-based classification

Figure 6: Supervised classification

110 points are collected for supervised training samples and classification accuracy. The collects samples are divided into two groups, $40 \%$ (44 points) of the training areas are used for the land cover classification and $60 \%$ (66 points) are used as accuracy points for accuracy assessment of the classification. The accuracy points are distributed across the entire input dataset using the equalized stratified random distribution sampling method (each class has the same number of points considered the most suitable for the study area. Table 2 presents the accuracy assessment results of each classification technique. 
Table 2: Accuracy assessment of the four classification techniques

\begin{tabular}{lcc}
\hline & $\begin{array}{c}\text { Overall } \\
\text { Accuracy }(\%)\end{array}$ & $\begin{array}{c}\text { Kappa } \\
\text { Coefficient }\end{array}$ \\
\hline Unsupervised ISODATA classification & 81.82 & 0.7818 \\
Unsupervised K-means classification & 77.27 & 0.7273 \\
Supervised pixel-based classification & 92.42 & 0.9091 \\
Supervised segment-based classification & 87.88 & 0.8545 \\
\hline
\end{tabular}

The pixel-based classification achieved the highest overall accuracy assessment for land cover mapping $(92.42 \%)$ with a 0.9091 kappa coefficient. The producer, user accuracy and kappa coefficient for each land cover class are generated for the four classification techniques as presents in Tables 3,4,5, and 6.

Table 3: Accuracy assessment of the ISODATA classification

\begin{tabular}{lccc}
\hline & $\begin{array}{c}\text { Producer } \\
\text { Accuracy }(\%)\end{array}$ & $\begin{array}{c}\text { User } \\
\text { Accuracy }(\%)\end{array}$ & $\begin{array}{c}\text { Kappa } \\
\text { Coefficient }\end{array}$ \\
\hline Water & 100 & 100 & 1 \\
Vegetation & 64.29 & 81.82 & 0.7692 \\
Barren with vegetation cover & 75 & 54.55 & 0.4828 \\
Bare Soil1 & 100 & 81.82 & 0.7895 \\
Bare Soil2 & 71.43 & 90.91 & 0.8846 \\
Urban and Built-up & 89.8 & 87.2 & 0.8757 \\
\hline
\end{tabular}

Table 4. Accuracy assessment of the K-Means classification

\begin{tabular}{lccc}
\hline & $\begin{array}{c}\text { Producer } \\
\text { Accuracy }(\%)\end{array}$ & $\begin{array}{c}\text { User } \\
\text { Accuracy }(\%)\end{array}$ & $\begin{array}{c}\text { Kappa } \\
\text { Coefficient }\end{array}$ \\
\hline Water & 100 & 100 & 1 \\
Vegetation & 53.33 & 72.73 & 0.6471 \\
Barren with vegetation cover & 57.14 & 36.36 & 0.281 \\
Bare Soil1 & 83.33 & 90.91 & 0.8889 \\
Bare Soil2 & 81.82 & 81.82 & 0.7818 \\
Urban and Built-up & 88.31 & 81.82 & 0.7857 \\
\hline
\end{tabular}

Table 5: Accuracy assessment of the pixel-based classification

\begin{tabular}{lccc}
\hline & $\begin{array}{c}\text { Producer } \\
\text { Accuracy }(\%)\end{array}$ & $\begin{array}{c}\text { User } \\
\text { Accuracy }(\%)\end{array}$ & $\begin{array}{c}\text { Kappa } \\
\text { Coefficient }\end{array}$ \\
\hline Water & 100 & 100 & 1 \\
Vegetation & 100 & 90.91 & 0.8929 \\
Barren with vegetation cover & 91.67 & 100 & 1 \\
Bare Soil1 & 100 & 72.73 & 0.6897 \\
Bare Soil2 & 73.33 & 100 & 1 \\
Urban and Built-up & 100 & 90.91 & 0.8929 \\
\hline
\end{tabular}

Table 6: Accuracy assessment of the segment-based classification

\begin{tabular}{|c|c|c|c|}
\hline & $\begin{array}{c}\text { Producer } \\
\text { Accuracy }(\%)\end{array}$ & $\begin{array}{c}\text { User } \\
\text { Accuracy }(\%)\end{array}$ & $\begin{array}{c}\text { Kappa } \\
\text { Coefficient }\end{array}$ \\
\hline Water & 100 & 100 & 1 \\
\hline Vegetation & 100 & 81.82 & 0.7895 \\
\hline Barren with vegetation cover & 84.62 & 100 & 1 \\
\hline Bare Soil1 & 100 & 72.73 & 0.6897 \\
\hline Bare Soil2 & 66.67 & 90.91 & 0.8824 \\
\hline Urban and Built-up & 90 & 81.82 & 0.7857 \\
\hline
\end{tabular}


Area of each land cover class using the four classification approaches are presented in Table 7.

Table 7: Area of land cover class in ( $\mathrm{km}^{2}$ and percent)

\begin{tabular}{|c|c|c|c|c|c|c|c|c|}
\hline \multirow{3}{*}{ Land Cover } & \multicolumn{4}{|c|}{ Unsupervised } & \multicolumn{4}{|c|}{ Supervised } \\
\hline & \multicolumn{2}{|c|}{ K-means } & \multicolumn{2}{|c|}{ ISODATA } & \multicolumn{2}{|c|}{ Pixel-based } & \multicolumn{2}{|c|}{ Segment-based } \\
\hline & $\mathrm{km}^{2}$ & $\%$ & $\mathrm{~km}^{2}$ & $\%$ & $\mathrm{~km}^{2}$ & $\%$ & $\mathrm{~km}^{2}$ & $\%$ \\
\hline Water & 1453.81 & 45.15 & 1390.73 & 43.19 & 1415.66 & 43.96 & 1422.1 & 44.17 \\
\hline Vegetation & 648.14 & 20.13 & 631.73 & 19.62 & 676.35 & 21 & 685.08 & 21.28 \\
\hline Barren with vegetation cover & 281.84 & 8.75 & 419.57 & 13.03 & 269.18 & 8.36 & 260.46 & 8.09 \\
\hline Bare Soil1 & 159.84 & 4.96 & 100.12 & 3.11 & 71.88 & 2.23 & 66.12 & 2.05 \\
\hline Bare Soil2 & 252.66 & 7.85 & 242.76 & 7.54 & 271.82 & 8.44 & 288.18 & 8.95 \\
\hline Urban and Built-up & 423.69 & 13.16 & 435.07 & 13.51 & 515.09 & 16 & 498.01 & 15.47 \\
\hline Total & 3219.98 & 100 & 3219.98 & 100 & 3219.98 & 100 & 3219.9 & 100 \\
\hline
\end{tabular}

Table 7 and Figure 8 manifested the land cover in the study area using the four classification techniques. Water class revealed approximately equally area in K-means $\left(1453.81 \mathrm{~km}^{2}\right)$, pixels-based $\left(1390.73 \mathrm{~km}^{2}\right)$ and segment-based $\left(1422.13 \mathrm{~km}^{2}\right)$ classifications. Whereas, in the ISODATA algorithms, the water class exhibited a smaller land cover area $\left(1390.73 \mathrm{~km}^{2}\right)$. Vegetation class showed closely equaled area ranged between 631.73 and $685.08 \mathrm{~km}^{2}$ in the four examined classification techniques. Barren lands with vegetation cover revealed almost equal area except in the ISODATA algorithms which presented an over-estimated area $\left(419.57 \mathrm{~km}^{2}\right)$. Bare soill presented different areas in all classification techniques, it was over-estimated in K-means classification (159.84 $\left.\mathrm{km}^{2}\right)$ and ISODATA $\left(100.12 \mathrm{~km}^{2}\right)$. Whereas bare soill was under-estimated in the pixel-based classification $\left(71.88 \mathrm{~km}^{2}\right)$ and in the segment-based classification $\left(66.12 \mathrm{~km}^{2}\right)$. Bare soil2 showed closely area size in the four classification techniques $\left(252.66,242.76,271.82\right.$ and $\left.288.18 \mathrm{~km}^{2}\right)$. Urban and built-up class presented nearly equaled area and under-estimated area in all techniques except in the pixel-based classification $\left(515.09 \mathrm{~km}^{2}\right)$ which revealed the optimal estimation according to the author's knowledge and experience about the study area.
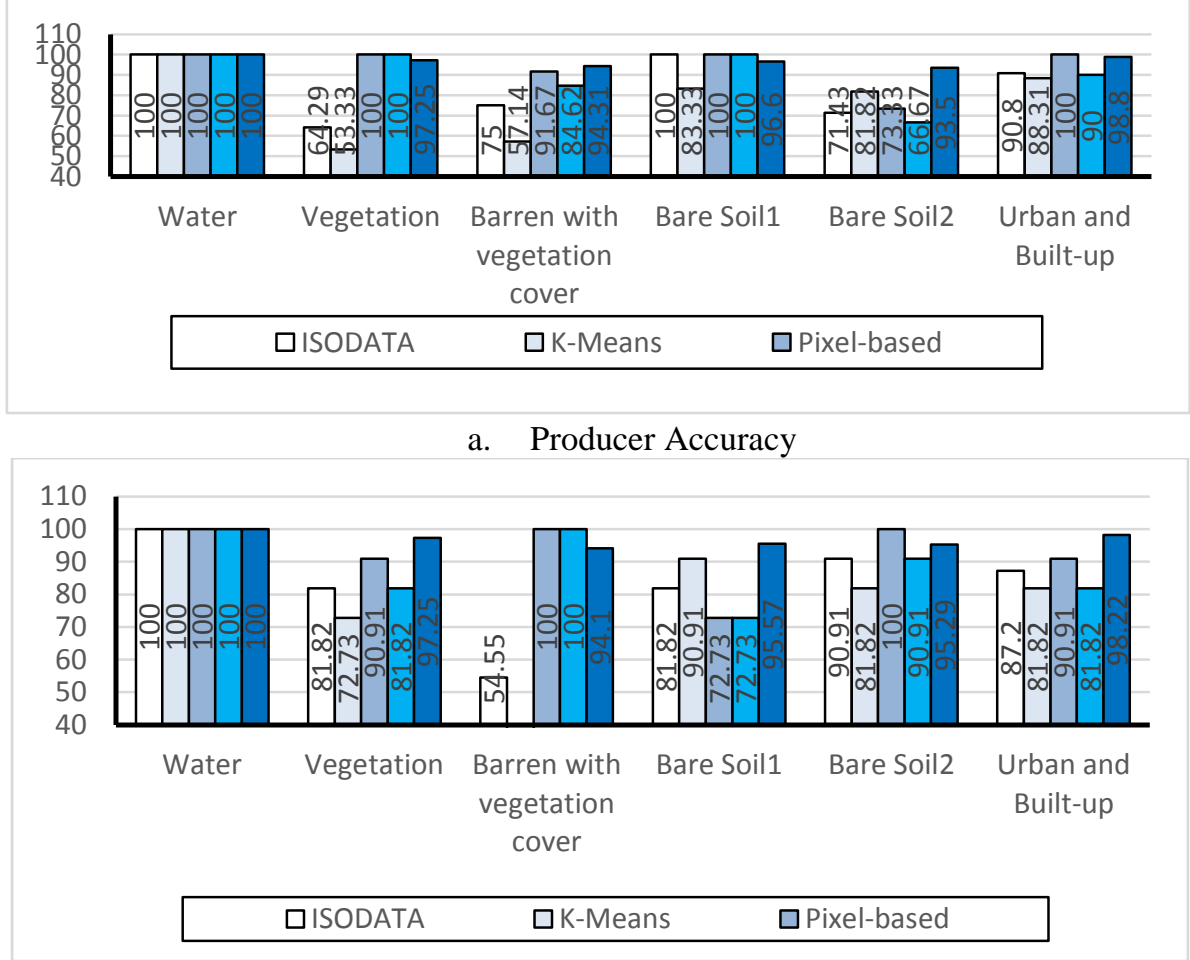

b. User Accuracy

Figure 7: Producer and user accuracy of four classification techniques 


\section{Conclusions and Recommendations}

The aim of this research is to evaluate and compare the accuracy of four image classification techniques to produce accurate land cover maps using Landsat-8 OLI/TIRS satellite image. The achieved results revealed that the correctness of the mapping of the land cover types is affected by the used classification techniques. The results of this study showed that the pixel-based classification is found to be superior in terms of the overall accuracy and kappa coefficient. Urban and built-up areas are best classified using the pixel-based classification. Applying different similarity tolerance generated different results in segment classification. However, the smaller value of similarity tolerance generated more detailed segment results and consequently difficult and tedious to find the best land cover segments. Also, for very high spatial-resolution data, the increased spatial resolution often comes at the expense of spectral information. Segment-based classification is used mainly in order to increase the accuracy in the classification of a high-resolution satellite. The ISODATA classifier exhibited better performance than the K-means classifier. However, the study showed many drawbacks of unsupervised techniques including K-means and ISODATA such as:

1. The misclassification of some land cover types due to the overlapping of classes and mixed pixels.

2. The misclassification of vegetation areas with the bare soil areas with natural and sparse vegetation cover due to the similarity of reflectance.

3. The discrimination between urban and bare soil areas was difficult because of the similarity of spectral signatures.

\section{Conflicts of Interest: None}

\section{References}

1. Abdu, K. K., Alias, R. A., Faiza, B., (2014): "A review and analysis of image segmentation approaches in change detection analysis". International Journal of Advancements in Research \& Technology, 3 (11), pp: 159 - 163.

2. Al-Ahmadi, F. S. and Hames, A. S., (2009): "Comparison of Four Classification Methods to Extract Land Use and Land Cover from Raw Satellite Images for Some Remote Arid Areas, Kingdom of Saudi Arabia". Earth Sci., 20 (1), pp: 167-191.

3. Alamri, S. S. A., Bin-Sama, A. S. A., Bin-Habtoor, A. S. Y., (2016). "Satellite Image Classification by Using Distance Metric". International Journal of Computer Science and Information Security (IJCSIS), 14(3).

4. Altaei, M. S. M., Ahmed, S. M., (2018). "Satellite Image Classification using Multi Features Based Descriptors". International Research Journal of Advanced Engineering and Science, 3(2), pp: 87-94.

5. Antunes, A.F.B., Lingnau C., Centeno, J.A.S., (2003): “Object Oriented Analysis and Semantic Network for High Resolution Image Classification”. Boletim de Ciências Geodésicas, 9(2), pp: 233242.

6. Blaschke, T., (2010): "Object based image analysis for remote sensing". ISPRS Journal of Photogrammetry and Remote Sensing, 65, pp: 2-16.

7. Campbell, J.B. (2002): Introduction to Remote Sensing - third edition. Taylor and Francis, London.

8. Choodarathnakara, A. L., Kumar, T. A., Koliwad, S., Patil, C. G., (2012) b: "Satellite Image Classification with Fuzzy Logic: from Hard to Soft Computing Situation". The International Journal of Computer Science \& Applications (TIJCSA), 1 (9), pp: $101-114$. 
9. Deur, M., Gašparovi', M., Balenovi', I., (2021): “An Evaluation of Pixel- and Object-Based Tree Species Classification in Mixed Deciduous Forests Using Pansharpened Very High Spatial Resolution Satellite Imagery “. Remote Sens., 13, 1868, https://doi.org/10.3390/rs13101868

10. Drăguţ, L., Tiede, D., Levick, S.R., (2010): "ESP: a tool to estimate scale parameter for multiresolution image segmentation of remotely sensed data". International Journal of Geographical Information Science, 24(6), pp: 859-871.

11. Eastman, J.R. and Laney, R.M., (2002): "Bayesian Soft Classification for Su b-Pixel Analysis: A Critical Evaluation". Photogrammetric Engineering \& Remote Sensing, 68 (11), pp: 1149 - 1154.

12. Foody, G. M., (1997): "Fully fuzzy supervised classifications of land cover from remotely sensed imagery with an artificial neural network". Neural Computing and Applications, 5, pp: 238-247.

13. Foody, G. M., (2020): "Explaining the unsuitability of the kappa coefficient in the assessment and comparison of the accuracy of thematic maps obtained by image classification". Remote Sensing of Environment, 239: 111630, https://doi.org/10.1016/j.rse.2019.111630

14. Frauman, E. and Wolff, E., (2005): "Segmentation of very high spatial resolution satellite images in urban areas for segments-based classification". In: Proc. International Symposium Remote Sensing and Data Fusion over Urban Areas and $5^{\text {th }}$ Intern. Symposium Remote Sensing of Urban Areas, Tempe, USA.

15. Goswami, A. K, Sharma, S., Kumar, P., (2014). "Nearest Clustering Algorithm for Satellite Image Classification in Remote Sensing Applications". International Journal of Computer Science and Information Technologies, 5 (3), pp: 3768-3772.

16. Hu, T., Wu, W., Liu, L., (2014): "Combination of Hard and Soft Classification Method Based on Adaptive Threshold", IGARSS.

17. Jensen, J. R. (1996). Introductory digital image processing. A remote sensing perspective (2nd ed.). New Jersey: Prentice-Hall.

18. Jog, S. and Dixit, M., (2016). "Supervised classification of satellite images". Conference on Advances in Signal Processing (CASP), pp: 93-98.

19. Laborte, A. G., Maunahan, A. A., Hijmans, and R. J., (2010): "Spectral Signature Generalization and Expansion Can Improve the Accuracy of Satellite Image Classification".

20. Lu D, Weng Q. A survey of image classification methods and techniques for improving classification performance. International Journal of Remote Sensing. 28(5), pp: 823-870.

21. Madhura M. and Venkatachalam, S., (2015): "Comparison of Supervised Classification Methods on Remote Sensed Satellite Data: An Application in Chennai, South India”. International Journal of Science and Research (IJSR), 4 (2).

22. Mahi, H., Farhi, N., and Labed, K., (2016). "Unsupervised Classification of Satellite Images using K-Harmonic Means Algorithm and Cluster Validity Index". EARSeL, eProceedings, 15, 1.

23. Matinfar, H.R., Sarmadian, F., Alavi Panah, S.K. and Heck, R.J. (2007): "Comparisons of ObjectOriented and Pixel-Based Classification of Land Use/Land Cover Types Based on Lansadsat7, ETM+ Spectral Bands (Case Study: Arid Region of Iran)". American-Eurasian J. Agric. \& Environ. Sci., 2 (4), pp: 448-456.

24. Mohamed, S. A. and El-Raey, M. E., (2018): "Monitoring and predicting Land Use/Land Cover Changes in Alexandria City using Land Cover Modeler and Markov Chain". Ass. Univ. Bull. Environ. Res., 22 (2).

25. Mohamed, S. A. and El-Raey, M. E., (2019a): "Vulnerability Parameters for Flash Floods Using GIS spatial modeling and Remotely Sensed Data in El-Arish City, North of Sinai-Egypt". Natural Hazards, https://doi.org/10.1007/s11069-019-03571-x 
26. Mohamed, S. A. and El-Raey, M. E., (2019b): "Land cover classification and change detection analysis of Qaroun and Wadi El-Rayyan lakes using multi-temporal remotely sensed imagery". Environmental Monitoring and Assessment, 2019, 191:229. https://doi.org/10.1007/s10661-0197339-x

27. Mohamed, S. A., (2019): “Application of Satellite Image Processing and GIS-Spatial Modeling for Mapping Urban Areas Prone to Flash Floods in Qena Governorate, Egypt". Journal of African Earth Sciences, https://doi.org/10.1016/j.jafrearsci.2019.05.015

28. Özkan, U. Y., Yeşil, A., (2016): "Forest stand delineation using Ikonos image and object-based image analysis". Journal of the Faculty of Forestry Istanbul University, 66(2), pp: 600-612.

29. Parraga-Alavaa, J., Alcivar-Cevallos, R., Vaca-Cardenas, L., Meza, J., (2021): "UrbangEnCy: An emergency events dataset based on citizen sensors for monitoring urban scenarios in Ecuador". Data in Brief, 34, 106693, https://doi.org/10.1016/j.dib.2020.106693

30. Patil, M. B., Desai, C. G. and Umrikar, B. N., (2012): "Image Classification Tool for Land Use / Land Cover Analysis: A Comparative Study of Maximum Likelihood and Minimum Distance Method". International Journal of Geology, Earth and Environmental Sciences, 2 (3), pp: 189-196.

31. Perumal, K., and Bhaskaran, R., (2010): "Supervised Classification Performance of Multispectral Images". Journal of Computing, 2 (2), pp: 124-129.

32. Phyo, T. Z, Khaing, A. S., Tun, H. M., (2015). "Classification of Cluster Area Forsatellite Image". International Journal of Scientific \& Technology Research, 4(06).

33. Prasad, S.V.S., Savithri, T. S., Krishna, I. V. M., (2015). "Techniques in Image Classification; A Survey". Global Journal of Researches in Engineering: Electrical and Electronics Engineering, 15(6).

34. Radoux, J. and Defourny, P., (2007): “A quantitative assessment of boundaries in automated forest stands delineation using very high-resolution imagery". Remote Sensing of Environment, 110 (4), pp: 468-475.

35. Richards, J.A., (1993): "Remote Sensing Digital Image Analysis: An Introduction". Berlin: Springer-Verlag.

36. Robertson, D. L., King, D. J., (2011): “Comparison of pixel- and object-based classification in land cover change mapping". International Journal of Remote Sensing, 32 (6), pp: 1505-1529.

37. Rokach, L., and Maimon, O., (2005): "Top-down induction of decision trees classifiers-A survey", IEEE Trans. Syst. Man Cybnet., Part-C, 35 (4), pp: 476-487.

38. Sampat, M. P., Bovik, A. C., Aggarwal, J. K., Castleman, K. R., (2005): "Supervised Parametric and Non-Parametric Classification of Chromosome Images", Pattern Recognition, 38 (8), pp: 12091223.

39. Sathya, P., and Deepa, V. B., (2017). "Analysis of Supervised Image Classification Method for Satellite Images". International Journal of Computer Science Research (IJCSR), 5(2), pp: 16-19.

40. Sonawane, M. S. and Dhawale, C. A., (2016): "Evaluation and Analysis of few Parametric and Nonparametric Classification Methods". Second International Conference on Computational Intelligence \& Communication Technology

41. Sunitha, A. and Suresh, B. G., (2015). "Satellite image classification methods and techniques: A review". International Journal of Computer Applications, 119(8), pp: 20-25.

42. Swain, P. H. (1973): "Pattern Recognition: A Basis for Remote Sensing Data Analysis" (LARS Information Note 111572). West Lafayette, Indiana: The Laboratory for Applications of Remote Sensing, Purdue University. 
43. Tangao, H., Jun-Feng, X., Deng-Rong, Z., Jie, W., Yu-Zhou, Z., (2013). "Hard and Soft Classification Method of Multi-Spectral Remote Sensing Image Based on Adaptive Thresholds". DOI: 10.3964/j.issn.1000-0593(2013)04-1038-05

44. Thakur, N., Maheshwari, D., (2017): “A Review of Image Classification Techniques”. International Research Journal of Engineering and Technology (IRJET), 4 (11), pp: 1588 - 1591.

45. Tonyaloğlu, E. E., Erdogan, N., Çavdar, B., Kurtşan, K., Nurlu, E., (2021): “Comparison of Pixel and Object Based Classification Methods on Rapideye Satellite Image”. Turkish Journal of Forest Science, 5(1), http://dx.doi.org/10.32328/turkjforsci.741030

46. Tou, Julius T., and Rafael C. Gonzalez. 1974. Pattern Recognition Principles. Reading, Massachusetts: Addison-Wesley Publishing Company.

47. Trias-Sanz, R., Stamon, G., Louchet, J., (2008): "Using colour, texture, and hierarchical segmentation for high-resolution remote sensing". ISPRS Journal of Photogrammetry and Remote Sensing, 63 (2), pp: 156-168.

48. Usman, B., (2013). "Satellite Imagery Land Cover Classification using K-Means Clustering Algorithm Computer Vision for Environmental Information Extraction". Computer Science and Engineering, 63, pp: 18671-18675.

49. Verma, N. K., Lamb, D.W., Reid, N., and Wilson, B., (2014): “A Comparative Study of Land Cover Classification Techniques for "Farmscapes" Using Very High Resolution Remotely Sensed Data". Photogrammetric Engineering \& Remote Sensing, 80 (5), pp: 461-470.

50. Vimala R, Marimuthu A, Venkateswaran S, Poongodi R., (2020): "Unsupervised ISODATA algorithm classification used in the Landsat image for predicting the expansion of Salemurban, Tamil Nadu". Indian Journal of Science and Technology, 3(16), pp:1619-1629, http://dx.doi.org/10.17485/IJST/v13i16.271

51. 56. Yousefia, S., Mirzaeeb, S., Tazehc, M., Pourghasemia, H., Karimid, H., (2015): "Comparison of different algorithms for land use mapping in dry climate using satellite images: a case study of the Central regions of Iran”. Desert, 20(1), pp: 1-10. 